\title{
Association between microsomal triglyceride transfer protein gene polymorphism and the biological features of liver steatosis in patients with Type II diabetes
}

\author{
S. Bernard ${ }^{1}$, S. Touzet ${ }^{2}$, I.Personne ${ }^{1}$, V. Lapras ${ }^{3}$, P.J. Bondon ${ }^{4}$, F. Berthezène ${ }^{1}$, P. Moulin ${ }^{1}$ \\ ${ }^{1}$ Department of Endocrinology and Nutrition, Cardiovascular Hospital Louis-Pradel, Bron, France \\ ${ }^{2}$ Department of Medical Information, Lyons, France \\ ${ }^{3}$ Department of Radiology, Antiquaille Hospital, Lyons, France \\ ${ }^{4}$ Biochemistry Laboratory, Antiquaille Hospital, Lyons, France
}

\begin{abstract}
Aims/hypothesis. Non-alcoholic steatohepatitis is frequent in Type II (non-insulin-dependent) diabetes mellitus and can lead to fibrosis and cirrhosis. The interindividual variability in the occurrence of nonalcoholic steatohepatitis suggests, however, a genetic modulation. Microsomal triglyceride transfer protein (MTP) is necessary for the assembly and secretion of VLDL and when the protein is not functional, such as in abetalipoproteinaemia, a steatohepatitis occurs. We therefore assessed the association between a functional polymorphism in the promoter region of $M T P$ gene $(-493 G / T)$ and the biological features of steatohepatitis in Type II diabetic patients.

Methods. We studied 271 patients with Type II diabetes. Determination of $-493 G / T$ polymorphism was made by PCR-RFLP. Increased liver enzymes were used as surrogates of liver steatosis and alanine aminotransferase concentration was the outcome variable for the multivariate analysis. Liver ultrasonography was available for a subgroup of patients with newly diagnosed diabetes.
\end{abstract}

Results. The proportion of patients with increased alanine aminotransferase was higher in $G G$ than in $G T$ and $T T$ subgroups $(23 \%, 11 \%$ and $6 \%$, respectively, $p=0.01$ ). Additionally, patients with high alanine aminotransferase concentrations were more likely to be young $(p=0.01)$, male $(p=0.001)$, obese $(p=0.04)$ and have low HDL-cholesterol $(p=0.01)$. In multivariate analysis, the MTP genotype was independently associated with alanine aminotransferase concentration $(p=0.0023)$ as well as sex and body mass index but not HDL-cholesterol.

Conclusion/interpretation. The -493 G/T MTP gene polymorphism is associated with biological surrogates of steatohepatitis in patients with Type II diabetes. The $G$ allele which is responsible for a decrease in $M T P$ gene transcription is prone to increase the intrahepatic triglycerides content, conferring by this a genetic susceptibility for steatohepatitis. [Diabetologia (2000) 43: 995-999]

Keywords Microsomal triglyceride transfer protein, Gene polymorphism, Genetic susceptibility, Nonalcoholic steatohepatitis, Type II diabetes mellitus
The term non-alcoholic steatohepatitis (NASH) describes liver disease histologically similar to alcoholic

Received: 23 February 2000 and in revised form: 17 April 2000

Corresponding author: Dr S. Bernard, Service d'endocrinologie et des maladies de la nutrition, Hôpital Cardiovasculaire Louis-Pradel, 28 avenue Doyen Lépine, 69500 Bron, France Abbreviations: ALAT, alanine aminotransferase; apoB, apolipoprotein B; ASAT, aspartate aminotransferase; $\gamma \mathrm{GT}$, gamma-glutamyl transferase; HDL-c, high density lipoprotein cholesterol; MTP, microsomal triglyceride transfer protein; $\mathrm{NASH}$, non-alcoholic steatohepatitis. liver disease occurring in patients without any history of excessive alcohol consumption [1,2]. Two main histological criteria are necessary for the diagnosis of NASH: fatty degeneration and inflammation or fibrosis. The latter criteria distinguishes NASH from simple steatosis which has a non-progressive course [3]. In western countries, NASH is a major cause of increased liver enzymes, next to alcohol consumption and hepatitis C [2]. It is frequently associated with obesity (40\%), Type II diabetes (20\%) and hyperlipidaemia $(20 \%)$ and can in the long term lead to cirrhosis in as many as 20 to $30 \%$ of cases [4-6]. It is hy- 
pothesised that occurrence of NASH requires a twohit process. The first one leads to hepatic steatosis and the second is required to turn steatosis into NASH [7]. Several overlapping causal factors emerged as candidates for NASH: (1) metabolic disorders, i.e. insulin resistance, abnormal fatty acid metabolism and intrahepatic accumulation of triglycerides [1, 8, 9], (2) increased oxydative stress [8, 10] and (3) increased production of cytokines [8, 11].

An increased concentration of triglycerides in hepatocytes is the result of increased synthesis or decreased secretion of VLDL. The microsomal triglyceride transfer protein (MTP) is necessary for assembly and secretion of VLDL from hepatocytes [12]. It has a key role in lipoprotein assembly, by transferring lipid (especially triglycerides) to nascent apoB. Liver steatosis is a characteristic of abetalipoproteinaemia, a rare autosomal recessive disease caused by mutations in the coding region of $M T P$ gene, resulting in a very low total cholesterol, undetectable plasma apolipoprotein B and fat malabsorption $[12,13]$.

Only a subgroup of subjects with Type II diabetes has NASH. It is more commonly encountered in those with the most severe insulin resistance syndrome. With similar clinical features and glycaemic control only a fraction of non-drinker Type II diabetic patients develop NASH, hence the hypothesis of a genetic susceptibility. A common functional polymorphism has been recently described in the promoter region of the $M T P$ gene $(-493 G / T)$ [14]. The $G$ allele is associated with decreased gene transcription compared with the $T$ allele. Therefore the $M T P$ gene is a good candidate for genetic susceptibility to NASH. The aim of this study was to investigate the relation between this functional MTP gene polymorphism and the biological surrogates of liver steatosis in Type II diabetic patients.

\section{Subjects and methods}

Subjects and blood samples. The patients were 271 consecutive Caucasian Type II diabetic patients (35-73 years old, 141 men and 130 women) who had at least one additional cardiovascular risk factor and participated in our local prospective study of Type II diabetes (DIACOR study), which aimed to test the predictive value of carotid intima-media thickness for cardiovascular events. Exclusion criteria were: ketonuria, fasting glycaemia above $15 \mathrm{mmol} / \mathrm{l}$, insulintherapy, concomitant illness (hepatic or renal insufficiency, neoplasia), history of severe hypertriglyceridaemia ( $>10 \mathrm{~g} / \mathrm{l}$ ), and heavy alcohol consumption ( $>40 \mathrm{~g} /$ day). All patients were questioned about their diet by a registered dietetician. Of the patients 48 were receiving hypolipidemic drug therapy and 225 being treated with oral antidiabetic agents. All had given written informed consent before DNA analysis and this study had the approval of our local ethics committee. Blood samples were drawn, after an overnight fast, into tubes containing EDTA and plasma was immediately separated by low-speed centrifugation.
-493 G/T MTP gene polymorphism. The polymorphism was detected by PCR-RFLP using a two-step nested PCR according to the method described by Karpe [14]. Briefly, the first step of the PCR amplified a 838 bp fragment with the following two primers: 5'-CCCTCTTAATCTCTTTCCTAGAA (MTP1) and 5'-AAGAATCATATTGACCAGCAATC (MTP-2). The second step of the PCR was then done using a 5' primer including a mutation to give rise to an Hph1 cutting site for the $G$ allele. The mutated primer was 5'-GGATTTAAATTTAAACTGTTAATTCATATCAC and the other primer 5'-AGTTTCACACATAAGGACAATCATCTA. This second step of the PCR amplified a $109 \mathrm{bp}$ fragment. The PCR products $(20 \mu \mathrm{l})$ were incubated with $\mathrm{Hph} 1$ (1 UI) for $2 \mathrm{~h}$ at $37^{\circ} \mathrm{C}$. Restriction fragment length polymorphism (RFLP) was analysed by high resolution using 3\% agarose gel as an electrophoretic media stained with ethidium bromide. The $T$ allele gave rise to a full-length fragment of $109 \mathrm{bp}$ and $G$ allele to two fragments of 89 and $20 \mathrm{bp}$. Samples with different PCR-RFLP patterns ( $G G$ and $T T$ homozygotes and $G T$ heterozygotes) were directly sequenced (Sanger method) to validate the PCRRFLP method [15].

Biological variables. Liver tests included alanine aminotransferase (ALAT), aspartate aminotransferase (ASAT), and gamma-glutamyl transferase ( $\gamma \mathrm{GT})$. Ferritinaemia and transferrin saturation were also measured in a subgroup of 107 patients with newly diagnosed Type II diabetes. None of them had an increase in transferrin coefficient above 0.50. Hepatitis B and C serology was done when serum ALAT, ASAT or $\gamma$ GT was above the upper normal range. Subjects with positive hepatitis serology were excluded. Haemoglobin $\mathrm{A}_{1 \mathrm{c}}\left(\mathrm{HbA}_{1 \mathrm{c}}\right)$ was evaluated by HPLC. Total cholesterol and triglycerides were measured using commercial kits (Biomérieux, Lyon, France). We obtained HDL-containing fractions after precipitation of apolipoprotein $\mathrm{B}$ (apoB)-containing lipoproteins by heparin/ $\mathrm{MnCl} 2$ [16].

Liver ultrasonography. Ultrasonography was systematically carried out in the subgroup of newly diagnosed diabetic patients (107/271) after an overnight fast. The operator was blind for liver enzymatic status. Liver hyperechoic structure was reported, specifying homogeneity or heterogenity of tissue. Echographic criteria for steatosis were an hyperechoic structure with a posterior absorption and attenuation of the diaphragmatic dome.

Statistical analysis. Categorical variables were assessed by the chi-squared test. Univariate regression analysis (correlation coefficient of Spearman) was used to analyse the relation between continuous variables. Comparison of means between genetic groups was tested by one-way analysis of variance. The association between MTP genotype and ALAT concentration was assessed by a multivariate analysis using a general linear logistic regression model, taking other clinical and biological characteristics into account [17]. The outcome factor, i.e. ALAT concentration was assessed as a dichotomous variable (cut-off: $45 \mathrm{U} / \mathrm{l}$ : upper concentration of the normal range in our enzymatic ALAT assay). The explanatory variables were: the MTP gene polymorphism, the clinical (sex, age, BMI and systolic blood pressure) and the biological ( $\mathrm{HbA}_{1 \mathrm{c}}$, HDL-c and triglycerides) characteristics of the patients. The effect of the $M T P$ gene polymorphism was assessed by a dichotomous variable: $G G$ homozygous compared with $G T$ heterozygous and $T T$ homozygous. The continuous clinical variables (age, BMI, systolic blood pressure) and the biological variables were standardised. The chi-squared tests for the parameter values were Wald tests. Results were presented with a level of significance considered at $p<0.05$. Analysis was done with Statistical Analysis Sofware (SAS Institute, Cary, N. C., USA). 


\section{Results}

The analysis of RFLP products showed similar allele frequencies for -493 G/T MTP gene polymorphism in this Type II diabetic cohort as previously described in healthy Caucasian subjects: $25 \%$ and $75 \%$ for $T$ and $G$ alleles, respectively [14]. Haplotype frequencies were also the same as those published previously (GG: $55.7 \%, G T: 37.6 \%, T T: 6.7 \%$ ) and were in the Hardy-Weinberg equilibrium [14]. There were no differences between genetic groups in sex distribution, age, alcohol consumption, BMI, systolic blood pressure, glycaemic control or lipid variables (Table 1). A similar proportion of subjects treated with oral antidiabetic agents was observed between genetic groups $(84 \%, 84 \%, 78 \%$, for $G G, G T$ and $T T$ groups, respectively, $p=0.77$ ). The proportion of subjects with increased ALAT or $\gamma$ GT was similar whether or not the patients were receiving lipid lowering therapy ( $p=0.59$ and $p=0.51$, respectively) moreover the percentage of patients receiving lipid lowering therapy was higher in $G T$ than $G G$ group (33\% and $18 \%$, respectively).

By contrast, mean concentrations of ALAT and $\gamma$ GT were higher in $G G$ than in $G T$ and $T T$ subgroups (Table 2) but ASAT only displayed a trend towards an increased mean concentration in $G G$ patients. Additionally, the $G G$ subgroup included a higher proportion of patients with increased enzyme concentrations or with ultrasonographic steatosis criteria (Table 3). The proportion of patients with increased ALAT and $\gamma \mathrm{GT}$ was not significantly different between $G T$ and $T T$ subgroups.

Univariate regression analysis showed that ALAT, $\gamma \mathrm{GT}$, ASAT, and ferritinaemia were all statistically significantly interrelated. We chose ALAT to reflect liver enzyme alterations because it is considered to be the best indirect biological index of NASH [2, 18]. Patients with increased ALAT were younger than those with normal values $(52 \pm 8$ vs $55 \pm 8$ years old, $\mathrm{p}=0.01$ ). The proportion of subjects with increased ALAT was higher among patients presenting ultrasonographic steatosis criteria $(40 \%$ vs $6 \%$, $p=0.0001$ ). Increased concentrations of ALAT were also significantly more frequent in men, obese subjects and those with low HDL-cholesterol (Table 4). The frequency of increased ALAT concentrations was not higher in hypertensive subjects (systolic blood pressure $>150 \mathrm{mmHg}$ ) or in patients with hypertriglyceridaemia (triglyceride $>2 \mathrm{~g} / \mathrm{l}$ ) or poor glycaemic control $\left(\mathrm{HbA}_{1 \mathrm{c}}>8 \%\right)$.

After excluding the observations where data were lacking, the analysis by the logistic model concerned 255 patients. Taking various confounding factors into account, ALAT concentration was statistically significantly linked to three variables: MTP genotype, sex and BMI (Table 5). These results were similar when MTP genotype was entered under the form
Table 1. Characteristics of patients according to MTP genotype

\begin{tabular}{lcccl}
\hline & $G G$ & $G T$ & \multicolumn{1}{l}{$T T$} & $p$ value $^{\mathrm{a}}$ \\
$n$ & 151 & 102 & 18 & \\
\hline Sex (men/women) & $75 / 76$ & $58 / 44$ & $8 / 10$ & 0.43 \\
Age (years) & $55 \pm 8.1$ & $54 \pm 8.3$ & $57 \pm 8$ & 0.31 \\
Alcohol (g/day) & $6 \pm 12$ & $6 \pm 11$ & $4 \pm 8$ & 0.82 \\
BMI $\left(\mathrm{kg} / \mathrm{m}^{2}\right)$ & $29 \pm 5$ & $29 \pm 5.5$ & $29 \pm 5$ & 0.96 \\
Systolic BP $(\mathrm{mm} H g)^{136 \pm 19}$ & $138 \pm 18$ & $136 \pm 18$ & 0.71 \\
HbA $_{1 \mathrm{c}}(\%)$ & $9.3 \pm 2$ & $8.9 \pm 2.2$ & $8.4 \pm 1.7$ & 0.16 \\
Total chol (g/l) & $2.1 \pm 0.4$ & $2.1 \pm 0.4$ & $2.0 \pm 0.4$ & 0.36 \\
Triglycerides $(\mathrm{g} / \mathrm{l})$ & $1.7 \pm 1.0$ & $1.8 \pm 1.3$ & $1.4 \pm 0.7$ & 0.20 \\
HDL-c $(\mathrm{g} / \mathrm{l})$ & $0.41 \pm 0.11$ & $0.41 \pm 0.11$ & $0.43 \pm 0.13$ & 0.82 \\
\hline
\end{tabular}

Values are expressed as means \pm SD. ${ }^{a} p$ is the degree of significance of the chi-squared test for the variable sex and oneway analysis of variance for the other variables. BP, blood pressure; chol, cholesterol

Table 2. Enzyme liver values and ferritinaemia according to $M T P$ genotype

\begin{tabular}{lccll}
\hline & $G G$ & $G T$ & $T T$ & $p$ value $^{\mathrm{a}}$ \\
$n$ & 151 & 102 & 18 & \\
\hline ALAT (U/l) & $36 \pm 30$ & $29 \pm 17$ & $25 \pm 15$ & 0.04 \\
ASAT (U/1) & $25 \pm 16$ & $22 \pm 8$ & $20 \pm 5$ & 0.13 \\
$\gamma$ GT (U/l) & $45 \pm 35$ & $35 \pm 24$ & $35 \pm 27$ & 0.04 \\
${\text { Ferritinaemia }(\mu \mathrm{g} / \mathrm{l})^{\mathrm{b}}}$ & $205 \pm 134$ & $178 \pm 137$ & $132 \pm 124$ & 0.22 \\
\hline
\end{tabular}

Values are expressed as means \pm SD. ${ }^{a} p$ is the degree of significance of the one-way analysis of variance. ${ }^{b}$ Ferritinaemia was available for a subgroup of 107 patients

Table 3. Per cent of subjects with increased concentration of liver enzymes or with ultrasonographic signs of steatosis according to $M T P$ genotype

\begin{tabular}{llccl}
\hline & & $\begin{array}{c}G G \\
\%(n)\end{array}$ & $\begin{array}{l}G T+T T \\
\%(n)\end{array}$ & $p$ value $^{\mathrm{a}}$ \\
\hline ALAT & normal & $77(116)$ & $90(108)$ & 0.004 \\
& high $^{\mathrm{b}}$ & $23(35)$ & $10(12)$ & \\
& total & $100(151)$ & $100(120)$ & \\
$\gamma \mathrm{GT}$ & normal & $71(107)$ & $82(98)$ & 0.04 \\
& high $^{\mathrm{c}}$ & $29(44)$ & $18(22)$ & \\
& total & $100(151)$ & $100(120)$ & \\
Ultrasono- & no & $43(27)$ & $61(27)$ & 0.05 \\
graphic stea- $^{\text {tosis criteriad }}$ & yes & $57(36)$ & $39(17)$ & \\
\hline
\end{tabular}

${ }^{a} p$ is the degree of significance of the chi-squared test when analyses were done on the basis of two genotype subgroups $(G G$ vs $G T+T T)$. ${ }^{\text {b }}$ ALAT: high $>45 \mathrm{U} / \mathrm{l} ;{ }^{\mathrm{c}} \gamma \mathrm{GT}$ : high: $>65 \mathrm{U} / \mathrm{l}$ for men and $>45 \mathrm{U} / \mathrm{l}$ for women. ${ }^{\mathrm{d}}$ Liver ultrasonography was available for the subgroup of patients with newly diagnosed diabetes $(n=107)$

of three subgroups $(G G, G T$ and $T T)$. Overall, when a subject was homozygous for the $G$ allele of the MTP gene promoter polymorphism the adjusted odds ratio for having an increased concentration of ALAT was 3.5 (95\% confidence limits: 1.6 to 7.9$)$ compared with $G T$ and $T T$ patients. 
Table 4. Per cent of patients with increased ALAT according to sex, BMI and concentrations of HDL-c

\begin{tabular}{|c|c|c|c|c|c|}
\hline & & ALAT & & Total & $p$ value $\mathrm{e}^{\mathrm{a}}$ \\
\hline & & $\begin{array}{l}\text { Normal } \\
(\leq 45 \mathrm{U} / \mathrm{l}) \\
\%(n)\end{array}$ & $\begin{array}{l}\text { High } \\
(>45 \mathrm{U} / \mathrm{l}) \\
\%(n)\end{array}$ & & \\
\hline Sex & $\begin{array}{l}\text { men } \\
\text { women }\end{array}$ & $\begin{array}{l}75 \text { (106) } \\
91(118)\end{array}$ & $\begin{array}{r}25(35) \\
9(12)\end{array}$ & $\begin{array}{l}100(141) \\
100(130)\end{array}$ & 0.001 \\
\hline BMI & $\begin{array}{l}\text { normal } \\
\text { high }^{\mathrm{b}}\end{array}$ & $\begin{array}{l}73(36) \\
59(131)\end{array}$ & $\begin{array}{l}27(13) \\
41(91)\end{array}$ & $\begin{array}{l}100(49) \\
100(222)\end{array}$ & 0.045 \\
\hline HDL-c & $\begin{array}{l}\text { normal } \\
\text { low }^{\mathrm{c}}\end{array}$ & $\begin{array}{l}89 \text { (112) } \\
77(112)\end{array}$ & $\begin{array}{l}11(14) \\
23(33)\end{array}$ & $\begin{array}{l}100(126) \\
100(145)\end{array}$ & 0.01 \\
\hline
\end{tabular}

${ }^{a} p$ value is the degree of significance of the chi-squared test. ${ }^{\mathrm{b}}$ High BMI: $>27 \mathrm{~kg} / \mathrm{m}^{2} .{ }^{\mathrm{c}}$ Low HDL-c: $<0.4 \mathrm{~g} / \mathrm{l}$

Table 5. Estimation of the effect of the $M T P$ genotype, clinical and biological characteristics of the patients on the ALAT concentrations by a logistic model

\begin{tabular}{lll}
\hline & $p$ value $^{\mathrm{a}}$ & $\begin{array}{l}\text { Adjusted } \\
\text { odds ratio }^{\mathrm{b}} \\
(95 \% \mathrm{CI})\end{array}$ \\
\hline MTP genotype & 0.0023 & $3.53(1.57-7.93)$ \\
$\mathrm{Sex}$ & 0.0004 & $4.76(2.02-11.24)$ \\
$\mathrm{BMI}$ & 0.0069 & $1.11(1.03-1.20)$ \\
Age & 0.15 & $0.97(0.92-1.01)$ \\
Systolic BP & 0.89 & $1.00(0.98-1.02)$ \\
HbA $_{1 \mathrm{c}}$ & 0.86 & $0.98(0.83-1.17)$ \\
HDL-c $_{\text {Triglycerides }}$ & 0.11 & $0.04(0.001-2.07)$ \\
\hline
\end{tabular}

${ }^{a} p$ value is the degree of significance of the Wald chi-squared test. ${ }^{b}$ Odds ratio for a one standard deviation increasing of the variable, except for $M T P$ gene and sex. For a given variable the odds ratio is adjusted for the other variables. BP, blood pressure

\section{Discussion}

We report that the $-493 G / T M T P$ gene polymorphism is associated with a higher proportion of subjects with increased liver enzymes (ALAT and $\gamma \mathrm{GT}$ ) in the $G G$ subgroup compared with the $G T$ and $T T$ groups. In this study we evaluate the potential effect of a common functional variant of $M T P$ gene on biological surrogates of liver steatosis.

Our data provide only indirect evidence of a link between a MTP gene polymorphism and NASH as liver biopsy specimens were not obtained for ethical reasons. Alanine aminotransferase is, however, commonly used as a surrogate of non-alcoholic liver steatosis and is considered to be a clinically relevant variable $[4,19,20]$. The concentration of ASAT which is more associated with alcohol consumption was increased in the same proportion of patients in the three genetic groups $[2,18]$. In the subgroup of patients with an ultrasonographic criteria of steatosis, increased ALAT concentration was more frequently observed and the incidence of $G G$ genotype was higher than in subjects with no ultrasonographic evidence of steatosis. It should be emphasised that the indication of ultrasonography was not based on increased ALAT concentration but newly diagnosed diabetes, lessening recruitment bias. In addition a trend was noted towards a statistically non-significant increase in ferritinaemia in the $G G$ subgroup correlating with the hepatosiderosis syndrome frequently associated with NASH [4, 21, 22]. This converging evidence makes it unlikely that it was by chance that there was a higher proportion of subjects with increased ALAT concentrations in the $G G$ subgroup. Furthermore, multivariate analysis strongly supports an independent contribution of the MTP genotype to increased ALAT concentrations in this Type II diabetic cohort at high risk for NASH.

The MTP gene is a good candidate for the genetic modulation of susceptibility to liver steatosis. A lack of functional MTP protein, such as encountered in abetalipoproteinaemia, is associated with hepatic steatosis [13]. Liver-specific inactivation of the $M T P$ gene has recently been shown to be associated with liver steatosis in the knockout mice [23]. Our data suggest that the $G$ allele of the MTP promoter polymorphism is associated with a higher risk of increased ALAT concentration. The $G$ allele encodes a decrease in $M T P$ gene transcription which would result in a relative decrease of MTP activity and, consequently, of VLDL assembly. In this way, the $G$ allele might contribute to intrahepatocyte triglyceride accumulation resulting in steatosis. The common occurrence of the $G$ allele is compatible with it being a potential causal factor of in NASH which is a frequent disorder in the general population. A moderate reduction in MTP activity as a consequence of this functional polymorphism might, by itself, be insufficient to induce steatosis but could become relevant when there are factors, such as alcohol consumption, insulin resistance or Type II diabetes, present. This is in agreement with a potential recessive effect of the $G$ allele and the absence of an evident allelic dose effect and possibly also with the recessive inheritance of steatosis in abetalipoproteinaemia [13].

The MTP gene is regulated by factors involved in steatohepatitis, especially alcohol and cytokines. It has been recently reported that ethanol, in addition to the well-known stimulation of hepatic lipogenesis, down-regulated MTP mRNA expression in HepG2 cells by a negative ethanol response element located near the $-493 G / T$ promoter polymorphism site (-642 to $-142 \mathrm{bp}$ ) [24]. It is however unlikely that this mechanism operated in our patients because none of them were heavy drinkers and the level of alcohol consumption was similar in the three genetic groups. Cytokines are thought to be implicated in the two-hit process of NASH, especially in inflammation. A recent study has shown that IL-1 and, to a lesser extent, TNF statistically significantly de- 
creased MTP mRNA expression in hamster liver [25]. Increased TNF $\alpha$ expression is thought to be implicated in the development of insulin resistance at the adipocyte level allowing speculation on the effect of a Type II diabetes-related overexpression of $\mathrm{TNF} \alpha$ in the facilitation of NASH. Furthermore $\mathrm{TNF} \alpha$ has been recently implicated in alcoholinduced liver injury in mice and a polymorphism located in the promoter region of $\mathrm{TNF} \alpha$ gene has been associated with susceptibility to alcoholic steatohepatitis [26, 27].

The MTP gene promoter polymorphism might also have an effect in steatoses other than NASH such as in alcoholic or viral steatosis. The negative effect of alcohol and increased cytokines in viral hepatitis C on $M T P$ gene transcription could be amplified in the presence of the $G$ allele for $-493 G / T$ MTP promoter polymorphism.

Our data suggest a relation between the MTP gene which conditions VLDL assembly and the incidence of steatosis in Type II diabetic patients. They do not preclude an effect of other candidate genes for susceptibility to liver steatosis such as those involved in fatty acid or triglyceride synthesis. Confirmation is needed in other populations at high risk of NASH such as non-diabetic insulin resistant obese subjects.

Acknowledgements. This work was supported by Lyons Hospital, National Centre for Scientific Research and Ipsen Biotech Laboratories. The authors thank nurses and laboratory technicians for technical assistance, Drs F. Bailly, F. Chapuis, L. Cotte, A. Girard and Professors M. Laville and C. Trepo for helpful discussions.

\section{References}

1. Sheth SG, Gordon FD, Chopra S (1997) Nonalcoholic steatohepatitis. Ann Intern Med 126: 137-45

2. James O, Day C (1999) Non-alcoholic steatohepatitis: another disease of affluence. Commentary. Lancet 353: $1634-1637$

3. Teli MR, James OF, Burt AD, Bennett MK, Day CP (1995) The natural history of nonalcoholic fatty liver: a follow-up study. Hepatology 22: 1714-1719

4. Bacon BR, Farahvash MJ, Janney CG, Neuschwander-Tetri BA (1994) Nonalcoholic steatohepatitis: an expanded clinical entity. Gastroenterology 107: 1103-1109

5. Caldwell SH, Oelsner DH, Lezzoni JC, Hessenheide EE, Battle EH, Driscoll CJ (1999) Cryptogenic cirrhosis: clinical characterization and risk factors for underlying disease. Hepatology 29: 664-669

6. Matteoni CA, Younossi ZM, Gramlich T, Boparai N, Lin YC, McCullough AJ (1999) Nonalcoholic fatty liver disease: a spectrum of clinical and pathological severity. Gastroenterology 116: 1413-1419

7. Day CP, James OF (1998) Steatohepatitis: a tale of two "hits"? Gastroenterology 114: 842-845

8. Wanless IR, Lentz JS (1990) Fatty liver hepatitis (steatohepatitis) and obesity: an autposy study with analysis of risk factors. Hepatology 12: 1106-1110

9. Arner P (1998) Not all fat is alike. Lancet 351: 13
10. Weltman MD, Farrell GC, Hall P, Ingelman-Sundberg M, Liddle C (1998) Hepatic cytochrome P450 2E1 is increased in patients with non-alcoholic steatohepatitis. Hepatology 27: $128-133$

11. Yang S, Lin HZ, Lane MD, Clemens M, Diehl AM (1997) Obesity increases sensitivity to endotoxin liver injury: implications for the pathogenesis of steatohepatitis. Proc Natl Acad Sci USA 94: 2257-2262

12. Wetterau JR, Lin MC, Jamil H (1997) Microsomal triglyceride transfer protein. Biochim Biophys Acta 1345: 136-150

13. Partin JS, Partin JC, Schubert WK, McAdams AJ (1974) Liver ultrastructure in abetalipoproteinemia: evolution of micronodular cirrhosis. Gastroenterology 67: 107-118

14. Karpe F, Lundahl B, Ehrenborg E, Eriksson P, Hamsten A (1998) A common functional polymorphism in the promoter region of the microsomal triglyceride transfer protein gene influences plasma LDL concentrations. Arterioscler Thromb Vasc Biol 18: 756-761

15. Sanger F, Nicklen S, Coulson AR (1977) DNA sequencing with chain-terminating inhibitors. Proc Natl Acad Sci USA 74: 5463-5467

16. Warnick GR, Nguyen T, Albers JJ (1985) Comparison of improved precipitation methods for cholesterol quantification in high-density lipoprotein. Clin Chem 31: 217-225

17. SAS/STAT User's Guide (1989) Version 6, 4th edn., vol 2, Cary, NC, SAS Institute Inc., pp 1071-1126

18. Sorbi D, Boynton J, Lindor KD (1999) The ratio of aspartate aminotransferase to alanine aminotransferase: potential value in differentiating nonalcoholic steatohepatitis from alcoholic liver disease. Am J Gastroenterol 94: 1018-1022

19. Powell EE, Cooksley WG, Hanson R, Searle J, Halliday JW, Powell LW (1990) The natural history of nonalcoholic steatohepatitis: a follow-up study of forty-two patients for up to 21 years. Hepatology 11: 74-80

20. Mathiesen UL, Franzen LE, Fryden A, Foberg U, Bodemar G (1999) The clinical significance of slightly to moderately increased liver transaminase values in asymptomatic patients. Scand J Gastroenterol 34: 85-91

21. George DK, Goldwurm S, McDonald GA et al. (1998) Increased hepatic iron stores in non-alcoholic steatohepatitis is associated with increased hepatic fibrosis. Gastroenterology 114: 311-318

22. Mendler MH, Turlin B, Moirand R et al. (1999) Insulin resistance-associated hepatic iron overload. Gastroenterology $117:$ : $1155-1163$

23. Raabe M, Véniant MM, Sullivan MA et al. (1999) Analysis of the role of microsomal triglyceride transfer protein in the liver of tissue-specific knockout mice. J Clin Invest 103: $1287-1298$

24. Lin MC, Li JJ, Wang EJ, Princler GL, Kauffman FC, Kung HF (1997) Ethanol down-regulates the transcription of microsomal triglyceride transfer protein gene. FASEB J 11: $1145-1152$

25. Navasa M, Gordon DA, Hariharan N et al. (1998) Regulation of microsomal triglyceride transfer protein mRNA expression by endotoxin and cytokines. J Lipid Res 39: $1220-1230$

26. Yin M, Wheeler MD, Kono H et al. (1999) Essential role of tumor necrosis factor $\alpha$ in alcohol-induced liver injury in mice. Gastroenterology 117: 942-952

27. Grove J, Daly AK, Bassendine MF, Day CP (1997) Association of tumor necrosis factor promoter polymorphism with susceptibility to alcoholic steatohepatitis. Hepatology 26: $143-146$ 